\title{
Sociocultural Influence on Obesity and Lifestyle in Children: A Study of Daily Activities, Leisure Time Behavior, Motor Skills, and Weight Status
}

\author{
Martin Hilpert ${ }^{a} \quad K^{2}$ rad Brockmeier ${ }^{b, c} \quad$ Sigrid Dordel ${ }^{d} \quad$ Benjamin Koch ${ }^{\text {a, e }}$ \\ Verena Weiß ${ }^{f} \quad$ Nina Ferraria, $c$ Walter Tokarskig Christine Grafa, c \\ anstitute of Movement and Neurosciences, German Sport University, Cologne, Germany; \\ bPediatric Cardiology, Heart Center, University Hospital of Cologne, Cologne, Germany; \\ ${ }^{c}$ Cologne Center of Prevention in Childhood and Adolescence, Heart Center, University \\ Hospital of Cologne, Cologne, Germany; ${ }^{d}$ Institute of School Sports and School

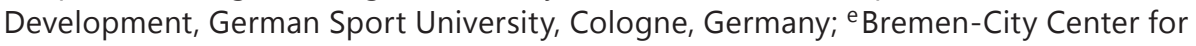

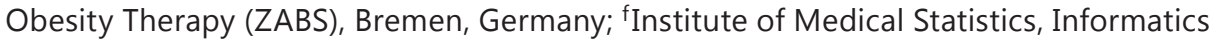 \\ and Epidemiology, University of Cologne, Cologne, Germany; ${ }^{9}$ Institute of European Sport \\ Development and Leisure Studies, German Sport University, Cologne, Germany
}

\section{Keywords}

Health promotion · Juvenile obesity $\cdot$ Sedentary lifestyle $\cdot$ Motor skills

\begin{abstract}
Background: Juvenile overweight is increasing, and effective preventive measures are needed. After years of arbitrarily assigning these measures disregarding socioeconomic and/or cultural differences, it has become necessary to tailor interventions more specific to these target groups. Providing data for such an intervention is the objective of this study. Methods: Influencing variables on children's weight status, motor skills and lifestyle have been analyzed among 997 first graders (53.2\% male) involved in the Children's Health InterventionaL Trial (CHILT). Results: Median age was 6.9 years; $7.3 \%$ were obese, $8.8 \%$ were overweight. Children with low socioeconomic status (SES) were more likely to be obese $(p=0.029)$. Low SES $(p<0.001)$, migration background $(p=0.001)$ and low sports activity levels $(p=0.007)$ contributed most to an increased consumption of television. Migration background $(p=0.003)$ and male gender $(p<$ 0.001 ) were the strongest factors in predicting a greater consumption of computer/video games. Children with higher SES $(p=0.02)$, lower BMI $(p=0.035)$, and males $(p=0.001)$ performed better in motor tests. Conclusion: Children with a low SES and migration background were more likely to exhibit unfavorable health behavior patterns, higher BMI scores, and poorer motor skills. Interventions should integrate motivational and targeting strategies and consider cultural and educational differences to address these vulnerable groups.
\end{abstract}


Hilpert et al.: Sociocultural Influence on Obesity and Lifestyle in Children: A Study of Daily Activities, Leisure Time Behavior, Motor Skills, and Weight Status

\section{Introduction}

Juvenile lifestyle has changed over recent decades towards a more sedentary lifestyle with a higher usage of audiovisual media. In a summary of different surveys (USA, UK, Europe), the amount of sedentary activities in 6- to 11-year-old children is approximately $6.4 \mathrm{~h} /$ day and in 16- to 19-year-old adolescents it is up to $7.9 \mathrm{~h} /$ day [1]. According to the NHANES study, $35 \%$ of children aged $2-5$ years, and up to $56 \%$ of children aged $12-15$ years watch television for more than $2 \mathrm{~h}$ /day [2]. Within the German KiGGS Study, 67.6\% of the 11- to 17-year-old boys spent more than $3 \mathrm{~h}$ /day watching television or videos or using computers, the internet and gaming consoles, while $34 \%$ spent more than $5 \mathrm{~h}$ of screen time per day [3]. Physical activity, on the other hand, is declining. Of boys between 3 and 10 years of age, 11.7\% participate in sports less than once or twice a week, and $11.7 \%$ do not engage in any sports at all, with even lower levels of physical inactivity in girls of the same age [4]. However, there is no clear association between media time and physical inactivity [5]. Rather, they seem to be independent variables in terms of the development of obesity [6]. During 2007, 16.4\% of children aged 10-17 years in the US were found to be obese and $15.3 \%$ overweight [7]. Throughout Europe, between 2007 and 2010, 12.8\% of children aged 2-9 years were overweight, and $7 \%$ were obese, with the highest prevalence in the southern and the lowest prevalence in the northern European regions of the study. In Germany the prevalence of overweight and obesity was $10.6 \%$ and $3.8 \%$ in boys and $12.9 \%$ and $5.6 \%$ in girls [8]. Primarily children from families with a lower socioeconomic status (SES) or migration background are overrepresented [8-10].

Obesity in childhood is associated with a wide range of health problems that are likely to last until later in life and to cause a significant increase in morbidity and mortality [11]. Also, there is a rising prevalence of the metabolic syndrome in the pediatric population [12]. Additionally, excess weight in children and adolescents has been shown to be associated with patterns of unfavorable metabolic markers during adolescence [13], suggesting that it might not only promote cardiovascular disease later in life but could also be associated with an early initiation of atherosclerosis.

A further possible consequence of inactivity is the decline in physical fitness. The endurance performance of children and adolescents decreased by $0.46 \%$ per year from 1970 to 2000 [14]. Reduced cardiovascular fitness is linked to a higher incidence of cardiovascular risk factors among adults [15] as well as among children and adolescents [16]. Daily physical activity during adolescence correlates positively with high-density lipoprotein and negatively with skin fold thickness and total high-density lipoprotein-cholesterol quotients [17]. In addition, the incidence of the metabolic syndrome was lower in adolescents with high levels of fitness $(2.6 \%)$ than in adolescents with moderate $(3.1 \%)$ or low levels of fitness (4.3\%) [18]. To counteract these developments, school-based programs have been developed, but their results are inconsistent [19]. They mostly lead solely to an increased awareness of nutrition and of the benefits of exercise but do not deliver longlasting improvements in measureable health factors, e.g. BMI, or laboratory parameters [20]. A possible reason for the failure might be the fact that decisive influencing factors, such as the parents' education levels and migration background $[3,4,9]$, have not sufficiently been taken into account. Tailoring school-based intervention programs to the groups of children that need them most might improve the quality and effectiveness of health promotion. Possible strategies to reach a better outcome could be school-based interventions with sports programs designed in a more motivating way. Also, the individual fitness level of the children and possible cultural aspects should be taken into account. For example, factoring in particular nutritional behavior or offering special swimming classes for Muslim girls might be part of the solution. 
Hilpert et al.: Sociocultural Influence on Obesity and Lifestyle in Children: A Study of Daily Activities, Leisure Time Behavior, Motor Skills, and Weight Status

However, a precise analysis of the influencing factors is required. Within this retrospective study of the CHILT-I data, factors have been analyzed that affect the lifestyles of children attending first grade. Innovatively, their effect on motor performance was assessed at the same time, and regression analysis was used, which displayed more complex relationships in the data.

\section{Participants and Methods}

\section{Sample and Study}

The study commenced in September 2001. 17 schools in the Cologne area took part in the CHILT program selection based on a cluster randomization [21]. This paper analyzes the baseline data. Informed consent was obtained from the children's parents and guardians. At the beginning of the 2001/2002 school year, anthropometric data for the children was gathered in classes, and their parents filled out a standardized questionnaire about leisure behavior and sports activities. In all, 997 children were included in the study, however, every variable was not available for every child. Other results have already been published elsewhere [21-23].

\section{Anthropometric Measurements}

Height and body weight were measured using a Seca stadiometer (type 225) and Seca scale (type 761). BMI was calculated and classified by the definition of Kromeyer-Hauschild et al. [24]; 'obese' was defined as BMI > 97th percentile, 'overweight' as BMI > 90th and $\leq 97$ th percentile, 'normal weight' as BMI $\geq 10$ th percentile and $\leq 90$ th percentile, and 'underweight' as BMI $<10$ th percentile.

SES

The children were given a 'low SES' rating if neither of their parents had graduated from a school with at least 9 years of schooling ('Hauptschulabschluss' in Germany), a 'middle SES' rating was given if at least one parent had graduated after 10 years of school ('Realschulabschluss') and a 'high SES' rating if at least one parent had graduated after 12 years of school ('Abitur') (on the basis of [25]).

\section{Migration Background}

Migration background was assumed if at least one of the following three criteria was met [26]: i) The children themselves had emigrated from another country, and at least one parent was not born in Germany; ii) both parents had emigrated to Germany; or iii) both parents did not possess German citizenship.

\section{Motor Skills}

The body coordination test for children (Körperkoordinationstest für Kinder) was used to examine gross motor development [27]. It consists of four items: balancing backwards, one-legged obstacle jumping, jumping from side to side, and sideway movements. This test may be used with children from 5 to 14 years of age $[27,28]$. The 6-min run was employed to analyze endurance levels as described elsewhere $[28,29]$.

\section{Daily and Leisure Time Activity Levels}

The questionnaire offered the following answers regarding the children's commute to school: 'on foot', 'by bicycle', 'by bus', 'by car'. 'On foot' and 'by bicycle' were deemed to be active ways of traveling to school, whereas 'by bus' and 'by car' were deemed to be non-active. The questionnaire asked about any organized sports activities the children participated in (times per week), unorganized but regular sports activities (times per week), and occasional sports activities (times per month). The activities were summarized and categorized as follows: 'low' = no leisure time activity or only occasional leisure time activity levels (= less than once a week), 'middle' = regular (and occasional) or organized leisure time activity levels (= at least once a week), and 'high' = organized and regular (or occasional) leisure time activity levels = at least twice a week) [23].

Determination of Sedentary Activities

The questionnaire queried the estimated number of minutes per day and also minutes per week the children spent watching television and playing video games/on the computer. In order to detect the signifi- 
cance of the respective variables, the time spent watching television as opposed to the time spent on the computer and playing video games was considered separately. Due to disproportionality between the mean reported per-week and per-day values, a mean value per day was calculated by aggregating the daily and weekly values in order to arrive at a more realistic estimated number of minutes per day.

\section{Data Analysis}

The descriptive statistics provided for quantitative data was the median with interquartile range and for qualitative data the absolute number and/or percent. Frequencies of qualitative variables in different groups were compared using the $\chi^{2}$ test. The extent of factors that may affect dependent variables was assessed using linear, logistic and multinomial logistic regression, depending on the level of measurement of the outcome variable. Dummy variables were used for categorical predictors with more than two categories. $P$ values $<0.05$ were considered statistically significant. Due to the explorative nature of this study, an $\alpha$-adjustment correction was not used for the multiple statistical analyses. All analyses were performed using the SPSS $20^{\circledR}$ statistical software (IBM Corp, Armonk, NY, USA).

\section{Results}

\section{Anthropometric Data}

Anthropometric data was available for 781 children (412 boys (52.8\%) and 369 girls (47.2\%)). The children's age was 6.9 (6.5-7.2) years, they were $1.23(1.2-1.3) \mathrm{m}$ tall, weighed $24.4(21.5-27.1) \mathrm{kg}$, and had a BMI of $15.8(14.8-17.2) \mathrm{kg} / \mathrm{m}^{2} .7 .2 \%(\mathrm{n}=56)$ were obese, $8.8 \%$ $(n=69)$ overweight, 75.9\% $(n=593)$ normal-weight, and 8.1\% $(n=63)$ underweight. Girls were younger, smaller, and lighter than the boys $(\mathrm{p}<0.05$ each); BMI did not differ.

\section{Sociocultural Variables}

The educational level of the parents (SES) was available for 427 (42.8\%) of the 997 children. $44.7 \%(\mathrm{n}=191)$ of the children's parents had a high, $41.5 \%(\mathrm{n}=177)$ a middle, and $13.8 \%(n=59)$ a low level of education.

In the obese group, significant differences between the SES levels were apparent $\left(\chi^{2}\right.$ test, $p=0.029)$. The lowest SES group had the highest percentage of obese children $(11.3 \%, n=6)$, followed by the middle SES group $(6.6 \%, n=12)$ and the high SES group $(2.6 \%, n=5)$. In the overweight or obese category, the difference was not significant $(\mathrm{p}=0.261)$.

Information about the migration background was given for $439(44.0 \%)$ of the 977 children. Children with a migration background formed $20.6 \%(n=90)$ of the total. In the obese group, the percentage of children with a migration background was higher $(8.4 \%, \mathrm{n}=$ 7 ) than that of the children without $(4.8 \%, \mathrm{n}=17)$. This difference was not significant $(\mathrm{p}=$ $0.187)$; nor was the difference for the overweight or obese category $(p=0.763)$.

\section{Television Time}

The children on average watched television on 48.9 (29.3-65.7) min/day. A multiple linear regression model $\left(n=256\right.$, missing $\left.n=741, R^{2}=0.193\right)$ was applied predicting the television viewing time for each day, taking into account the following variables: age, BMI, SES, migration background, gender, and sports activity level. According to that model, the daily television consumption time was $28 \mathrm{~min} /$ day longer in the low SES than fin the high SES group ( $\mathrm{p}<0.001), 10 \mathrm{~min} /$ day longer in the middle SES than in the low SES group $(\mathrm{p}=0.095$, significant at the $10 \%$ level), $21 \mathrm{~min} /$ day longer in children with a migration background than in their counterparts $(p=0.001)$, and $16 \mathrm{~min} /$ day longer in the low sports activity level than in the high sports activity group ( $\mathrm{p}=0.007)$. 
Hilpert et al.: Sociocultural Influence on Obesity and Lifestyle in Children: A Study of Daily Activities, Leisure Time Behavior, Motor Skills, and Weight Status

\section{Video Game/Computer-Playing Behavior}

The children used computer and/or video games for 9.3 (0.0-22.8) min/day. A multiple regression model $\left(n=232\right.$, missing $\left.n=745, R^{2}=0.125\right)$ was created to predict the daily computer/video game playing time with the following independent variables: age, BMI, SES, migration, gender, and sports-activity level. The daily computer/video game consumption time predicted by the model was $9 \mathrm{~min}$ /day longer for children with a migration background than for those without $(p=0.003)$ and $9 \mathrm{~min} /$ day longer for boys than for girls $(p<0.001)$.

\section{Leisure-Time Sports Activity Levels}

The leisure activity level was low for $21.4 \%$ of the children, mid-range for $50.3 \%$, and high for $28.3 \%$. A multinomial logistic regression model $\left(n=206\right.$, missing $\left.n=791, R^{2}=0.135\right)$ was calculated to predict the sports activity level using age, BMI, television time (h/day), computer/ video game time (h/day), SES, migration background, and gender as the independent variables. Children with a migration background had a 4.6-fold higher probability of being in the low as opposed to the high sports activity level than their counterparts. They also had a 4.4-fold higher probability of being in the mid-range sports activity level as opposed to high sports activity level than those without a migration background. For every additional hour of television consumption, the probability of being in the low rather than the high sports activity level rose four-fold. For every additional hour of computer/video game consumption, the probability of being in the high as opposed to the low sports activity level rose by a factor of 7.5.

\section{Motor Skills}

The average motor quotient (MQ) was 94.0 (84.0-105.9). A multiple regression model (n $=202$, missing $\mathrm{n}=795, \mathrm{R}^{2}=0.133$ ) was calculated to predict the MQ using the following independent variables: age, BMI, SES, migration background, gender, daily television time, daily computer/video game time, and sports activity level. Children in the middle SES level had an 8 point higher MQ than those in the low SES level $(p=0.020)$. Girls had a 7 point lower MQ than boys $(\mathrm{p}=0.001)$, and for every additional BMI point, the MQ was 0.8 points lower $(\mathrm{p}=$ 0.091 , significant to the level of $10 \%$ ).

The average distance run in 6 min was 839.0 (765.0-918.0) $\mathrm{m}$. A multiple regression model ( $n=186$, missing $n=811$ ) was calculated to predict the result of the run using the following variables: age, BMI, SES, migration background, gender, daily television time, daily computer/video game time, and sports activity level. For every additional BMI point, the children ran $9 \mathrm{~m}$ less in $6 \mathrm{~min}(\mathrm{p}=0.035)$; girls ran $33 \mathrm{~m}$ less than boys $(\mathrm{p}=0.047)$.

\section{Traveling to School}

$70.4 \%$ of the children commuted actively, $29.6 \%$ did not. A logistic regression model (n $=207$, missing $n=790, R^{2}=0.08$ ) was calculated to predict commuting mode as the dependent variable and age, BMI, SES, migration background, gender, television time (h/day), and computer/video game time (h/day) as the independent variables. Age was the only significant factor. For every additional year of age, the probability that a child uses a non-active mode of commuting to school rose by a factor of 2.5 .

\section{Discussion}

Physical activity is important in terms of children's physical and psychosocial development [30]. Motor-skill deficits resulting from a lack of exercise in turn cause children to enjoy exercise less and to increasingly withdraw from available exercise programs in favor of a more inactive lifestyle. In the context of increasing juvenile adiposity, numerous programs 
have been offered to prevent this development; however, only a few have been published in scientific journals. Even though some of the lifestyle modification programs have shown success regarding a decrease in BMI, a perfect solution has not emerged. Beginning these programs at an early age, such as primary school, as well as combining nutrition and physical activity has shown to yield the best results [31, 32]. However, particular target groups, such as those with a migration background or low SES, remain hardly accessible. In order to tailor interventions specifically, it is important to conduct more research about these groups. Therefore, relationships between selected lifestyle parameters, anthropometric data and, as an innovation, motor skills were analyzed while taking sociocultural aspects into account. Baseline data agreed with findings already known, e.g., a clear connection between low SES as well as migration background and overweight/obesity. While several studies performed in Germany [33-36] demonstrated comparable results, this innovative study adds additional data for a younger group of children. On an international level, several studies point in a similar direction for children with a migration background, specifically in the US [37] and in European countries [38-40]. Also, the inverse association between parental education as an indicator of SES and obesity confirms the IDEFICS data from various European studies [8].

In this study, the time children spent watching television was inversely related to SES and higher for those with a migration background compared to their counterparts. Other German studies revealed a similar relationship for SES [3, 34]. Lampert et al. [3] demonstrated that video game/computer time was higher in children with a migration background, a finding that reflects the results of this study. Since these children are more likely to live in families with lower SES [41], this finding might be biased by this parameter. A new insight was gained through the analysis in this study, which showed that both SES and a migration background independently affect the time spent watching television in an unfavorable way. With a higher computer/video game consumption the probability of being in a higher sports activity level rose in our study. This can be interpreted in a way that computer/video game consumption not necessarily means inactivity and underlines the necessity to differentiate between the various forms of screen time.

As in previous studies from Germany [4] and other European countries [38], children with a migration background were significantly less likely to participate in organized sports or to be physically active in their leisure time. The latter was a main factor in the lower leisure time activity level ratings for these children in our study. One reason for lower participation in organized sports among children with a migration background, who are more likely to possess a lower SES than non-migrants [41], is probably the financial barrier, i.e., membership fees are often too expensive [4]. The cultural or religious environments of children with a migration background may also be limiting [42].

The correlation between BMI and motor abilities, showing markedly poorer gross motor development and endurance capacities in overweight and obese children, have been revealed in the CHILT project and discussed elsewhere [23]. This study confirmed these findings with the regression model, thus adding statistic reliability due to the higher complexity of the method.

Sociocultural variables also affect motor skills. The higher the SES, the higher the gross motor development (MQ). However, this effect was not shown for endurance capacities. In addition, migration was not established as a significant influencing factor in the regression models for physical performance. Even though the Motoric Module (MoMo; KiGGS study [43]) used different physical tasks to assess motor skills, it was in line with findings in this study: children with low SES turned out to have poorer motor abilities throughout. These results may be used as a guide by policy makers to implement intervention programs tailored especially to the less favored children of low SES. This could give them the chance to develop in a healthy way and to close the gap between children with low and high motor skills. 
The older the children were, the less likely they were to commute actively. Findings in the KOPS study [25] were similar. While KOPS focused on 14-year-old adolescents, this innovative study could confirm the results to be true for a younger population as well. Since active commuting time represents a high percentage (28.4\% in [25]) of the daily physical activity time, it can be considered an important factor in meeting the daily goals for physical activity. The relationship between active commuting and a long-term reduction of cardiovascular risk [44] has been established, thus underlining its importance to health promoting behavior.

\section{Limitations}

The authors are aware that cross-sectional studies are not able to establish any causeand-effect relationships.

It is not unusual that answers which are deemed socially desirable are provided in response to questionnaires [45]; thus it is more likely that a parent would exaggerate activity and understate screen time than the reverse. Information from the parents provided in the questionnaire is subjective, making reporting bias possible. Using questionnaires is common for the assessment of SES, but future measures of physical activity should therefore resort to objective measures such as heart rate, pedometer, or accelerometer monitoring [46]. More accurate tools should also be used to measure media usage [47]. For this reason the reported media times and physical activity times might be conservative, thus trivializing the magnitude of children's high levels of inactivity and low levels of activity.

A study of children analyzing self-reported sedentary behavior and its relation to objectively measured sedentary time revealed a significant positive association for self-reported television viewing and playing video games and a negative association for self-reported talking on the phone and using the computer/internet [48]. This study suggests our assessment of television viewing to be a good measure of sedentary behavior. Our category of video game / computer usage, though, should probably be subdivided into more accurate classifications. Considering changes in media use over the last decade (especially increasing availability of smartphones and tablets), the fact that our data was collected in 2001 could be seen as a limitation. As mentioned above, talking on the phone and using a computer/internet seem to not contribute to the problem of sedentary behavior since a negative association to objectively measured sedentary time was shown [48]. In addition, development of new technology increasingly allows interventions and improvements of health and health-promoting behaviors, thus improving long-term weight and physical activity management in a costeffective way. This may also contribute to the reduction of cardiovascular risk factors [49, 50]. In addition, for more accurate collection of data on daily activities and behavior, the smartphone can be used [51]. Further possibilities to use this type of technology in childhood remains to be investigated.

The relatively large number of values missing for individual variables may also constitute a further possible weakness, thus a selection bias cannot be excluded. Only the parents' school leaving certificates were used to indicate SES, whereas income was not included in the rating, as was done in other studies [33]. The review by Shrewsbury et al. [52] revealed that the parents' levels of education are more consistently inversely associated with adiposity than other indicators. Using parents' incomes or occupations as indicators, the relationship to adiposity was more evenly distributed between an inverse association and no association. A probable reason for this is that the education level, including knowledge and habits, is a much stronger determinant of a health-related lifestyle than income [53]. Another problem when asking for income in a study is the high nonresponse rate due to the sensitive nature of this question [54], which may lead to further bias due to higher missing values. 
The present analysis allows important aspects for school-based interventions to be established. Especially children with a low SES and a migration background as well as those possessing high BMI rates are more likely to have unhealthy lifestyles and exhibit poor motor skills. The fact that from the outset these groups are less well-off must also be taken into account. It is well known that obese children in the first year at school already have a markedly higher media consumption. This in turn is ultimately related to a less active leisure time behavior and poorer motor skills, at least in these schools, and must be made clear to the policy makers. Because this group possesses a lower SES and/or is more likely to have a migration background, the initial contact and mediation must be target group-oriented. School-based programs have the advantage that all children, even those from socially disadvantaged families and/or with a migration background, can be reached [55]. In Germany, the number of all-day schools is growing, which offers the opportunity to make more organized sports programs available. For example, this allows financial barriers to be circumvented. To close or to prevent the gap between children with good motor skills and those with poor motor skills from continuing to grow children should be promoted in specific physical activity groups. This would especially target the individuals of low SES who were shown to be most in need. Sports programs should be designed in a more motivating way, especially for the children with lower motor abilities, and adapted to the individual fitness levels for promoting development and avoiding excessive demand. Considering special cultural barriers in children with a migration background might be an important measure to reach those groups more effectively. Special swimming classes for Muslim girls would be an example to circumvent those barriers. Taking individual cultural aspects like nutritional behavior into account might also be part of the solution.

The participation of the parents constitutes a factor that is paramount to the success of an intervention program $[20,56,57]$. They are lifestyle role models while at the same time they control television/computer consumption and set the boundaries for active leisure time behavior.

A comprehensive analysis of the target group and the consideration of relevant influencing factors, e.g, how well these children and families can be addressed, is necessary. A case management-based, interdisciplinary, intensive, and individualized procedure, such as the trans-theoretical model of behavior change by Prochaska and DiClemente [58], may be useful. It describes behavior-modifying steps through which people may progress to achieve health-related changes. It would be possible for practitioners to employ this model in the effective management of appropriate interventions [59]. Only when all these factors have been considered and tailored intervention programs have been implemented, will it be possible to help all children develop more healthily on a sustained basis, especially those from families with a lower SES and/or migration background. In modern-day healthcare, only a small fraction of the resources spent on the consequences of an unhealthy lifestyle (e.g. diabetes-related complications) are invested in strategies to prevent obesity, diabetes, and other chronic diseases. Aside from the negative consequences on health and well-being, the massive economic burden caused by diseases associated with an unhealthy lifestyle calls for the implementation of a wide range of cost-effective corrective interventions by our governments [60]. This financial strain does not only affect the healthcare system directly but also the individual, family, and community levels. Utilizing the history of tobacco control in the recent decades as a role model, the government interventions should be aimed at economic, political, social, psychological, and biological factors [11]. The innovation of the present study was the analysis of factors that affect the lifestyles of children attending first grade and their effect on motor performance at the same time. The objective was to meet the complexity of the data and thus to generate knowledge to develop tailored intervention programs in the future. 
Hilpert et al.: Sociocultural Influence on Obesity and Lifestyle in Children: A Study of Daily Activities, Leisure Time Behavior, Motor Skills, and Weight Status

\section{Acknowledgments}

We are grateful for the support provided by the AOK Rheinland/Hamburg (Cologne Office), Sportärztebund Nordrhein, the Förderverein des Herzzentrums Köln, and the IMSIE of the Cologne University. We thank the students, teachers and parents who took part in this study. We would also like to thank David G. Tansey, Anthony J. King, and Erica and Daniel Landerson for critically reviewing the manuscript.

\section{Ethical Standards}

The authors assert that all procedures contributing to this work comply with the Helsinki Declaration of 1975, as revised in 2008, and have been approved by an independent Ethics Committee at the German Sport University of Cologne. Informed consent was obtained from the children's parents and guardians.

\section{Financial Support}

Funding of the CHILT-I project was provided by the Heart Center, University Hospital of Cologne, Cologne, Germany.

\section{Disclosure Statement}

The authors declare no conflict of interest.

\section{References}

1 Pate RR, Mitchell JA, Byun W, Dowda M: Sedentary behaviour in youth. Br J Sports Med 2011;45:906-913.

2 Sisson SB, Church TS, Martin CK, Tudor-Locke C, Smith SR, Bouchard C, Earnest CP, Rankinen T, Newton RL, Katzmarzyk PT: Profiles of sedentary behavior in children and adolescents: the US National Health and Nutrition Examination Survey, 2001-2006. Int J Pediatr Obes 2009;4:353-359.

3 Lampert T, Sygusch R, Schlack R: Use of electronic media in adolescence. Results of the German health interview and examination survey for children and adolescents (KIGGS) (in German). Bundesgesundheitsbl Gesundheitsforsch Gesundheitsschutz 2007;50:643-652.

4 Lampert T, Mensink GB, Romahn N, Woll A:Physical activity among children and adolescents in Germany. Results of the German health interview and examination survey for children and adolescents (KIGGS) (in German). Bundesgesundheitsbl Gesundheitsforsch Gesundheitsschutz 2007;50:634-642.

5 Marshall SJ, Biddle SJ, Gorely T, Cameron N, Murdey I: Relationships between media use, body fatness and physical activity in children and youth: a meta-analysis. Int J Obes Relat Metab Disord 2004;28:1238-1246.

6 Graf C, Dordel S: Therapy of juvenile obesity from the sports medicine/science viewpoint (in German). Bundesgesundheitsbl Gesundheitsforsch Gesundheitsschutz 2011;54:541-547.

7 Data Resource Center for Child and Adolescent Health: Child and Adolescent Health Measurement Initiative. 2007 National Survey of Children's Health. www.childhealthdata.org/browse/survey?s=2 (last accessed April 27, 2017).

8 Ahrens W, Pigeot I, Pohlabeln H, De Henauw S, Lissner L, Molnar D, Moreno LA, Tornaritis M, Veidebaum T, Siani A, consortium I: Prevalence of overweight and obesity in European children below the age of 10. Int J Obes (Lond) 2014;38(suppl 2):S99-107.

9 Kurth BM, Schaffrath Rosario A: The prevalence of overweight and obese children and adolescents living in Germany. Results of the German health interview and examination survey for children and adolescents (KIGGS) (in German). Bundesgesundheitsbl Gesundheitsforsch Gesundheitsschutz 2007;50:736-743.

10 Kleiser C, Schaffrath Rosario A, Mensink GB, Prinz-Langenohl R, Kurth BM: Potential determinants of obesity among children and adolescents in Germany: Results from the cross-sectional KIGGS study. BMC Public Health 2009;9:46.

11 Yach D, Stuckler D, Brownell KD: Epidemiologic and economic consequences of the global epidemics of obesity and diabetes. Nat Med 2006;12:62-66.

12 Kursawe R, Santoro N: Metabolic syndrome in pediatrics. Adv Clin Chem 2014;65:91-142.

13 Nagel G, Rapp K, Wabitsch M, Buchele G, Kroke A, Zollner I, Weiland SK, Koenig W: Prevalence and cluster of cardiometabolic biomarkers in overweight and obese schoolchildren: results from a large survey in southwest Germany. Clin Chem 2008;54:317-325. 
Hilpert et al.: Sociocultural Influence on Obesity and Lifestyle in Children: A Study of Daily Activities, Leisure Time Behavior, Motor Skills, and Weight Status

14 Tomkinson GR: Global changes in anaerobic fitness test performance of children and adolescents (19582003). Scand J Med Sci Sports 2007;17:497-507.

15 Myers J, Prakash M, Froelicher V, Do D, Partington S, Atwood JE: Exercise capacity and mortality among men referred for exercise testing. N Engl J Med 2002;346:793-801.

16 Tomkinson G: Aerobic fitness thresholds for cardio metabolic health in children and adolescents. Br J Sports Med 2011;45:686-687.

17 Twisk JW, Kemper HC, van Mechelen W: Tracking of activity and fitness and the relationship with cardiovascular disease risk factors. Med Sci Sports Exerc 2000;32:1455-1461.

18 Pan Y, Pratt CA: Metabolic syndrome and its association with diet and physical activity in US adolescents. J Am Diet Assoc 2008;108:276-286; discussion 286.

19 Dobbins M, Husson H, DeCorby K, LaRocca RL: School-based physical activity programs for promoting physical activity and fitness in children and adolescents aged 6 to 18. Cochrane Database Syst Rev 2013;2:CD007651.

20 Oude Luttikhuis H, Baur L, Jansen H, Shrewsbury VA, O’Malley C, Stolk RP, Summerbell CD: Interventions for treating obesity in children. Cochrane Database Syst Rev 2009:CD001872.

21 Graf C, Koch B, Falkowski G, Jouck S, Christ H, Staudenmaier K, Tokarski W, Gerber A, Predel HG, Dordel S: School-based prevention: effects on obesity and physical performance after 4 years. J Sports Sci 2008;26: 987-994.

22 Graf C, Dordel S: The CHILT I project (Children's Health Interventional Trial). A multicomponent intervention to prevent physical inactivity and overweight in primary schools (in German). Bundesgesundheitsbl Gesundheitsforsch Gesundheitsschutz 2011;54:313-321.

23 Graf C, Koch B, Kretschmann-Kandel E, Falkowski G, Christ H, Coburger S, Lehmacher W, Bjarnason-Wehrens B, Platen P, Tokarski W, Predel HG, Dordel S: Correlation between BMI, leisure habits and motor abilities in childhood (CHILT-project). Int J Obes Relat Metab Disord 2004;28:22-26.

24 Kromeyer-Hauschild K, Wabitsch M, Kunze D: Perzentile für den Body Mass Index für das Kindes- und Jugendalter unter Heranziehung verschiedener deutscher Stichproben. Monatsschr Kinderheilkd 2001;149:807818.

25 Landsberg B, Plachta-Danielzik S, Much D, Johannsen M, Lange D, Müller MJ: Associations between active commuting to school, fat mass and lifestyle factors in adolescents: The Kiel Obesity Prevention Study (KOPS). Eur J Clin Nutr 2008;62:739-747.

26 Schenk L, EllertU, Neuhauser H: Children and adolescents in Germany with a migration background. Methodical aspects in the German health interview and examination survey for children and adolescents (KIGGS) (in German). Bundesgesundheitsbl Gesundheitsforsch Gesundheitsschutz 2007;50:590-599.

27 Schilling F: Körperkoordinationstest für Kinder. KTK. Manual. Weinheim, Beltz, 1974.

28 Beck J, Bös K: Normwerte der motorischen Leistungsfähigkeit. Köln, Sport und Buch Straß, 1995.

29 Bös K: Motorische Tests, 2nd ed. Göttingen, Hogrefe, 2001.

30 Timmons BW, Naylor PJ, Pfeiffer KA: Physical activity for preschool children - how much and how? Can J Public Health 2007; 98(suppl 2):S122-134.

31 Colquitt JL, Loveman E, O'Malley C, Azevedo LB, Mead E, Al-Khudairy L, Ells LJ, Metzendorf MI, Rees K: Diet, physical activity, and behavioural interventions for the treatment of overweight or obesity in preschool children up to the age of 6 years. Cochrane Database Syst Rev 2016;3:CD012105.

32 Klein D, Manz K, Ferrari N, Struder H, Graf C: Effects of health promotion projects in preschools on body mass index and motor abilities. J Sports Med Phys Fitness 2015;55:103-112.

33 Lampert T, Kurth BM: Sozialer Status und Gesundheit von Kindern und Jugendlichen. Ergebnisse des Kinderund Jugendgesundheitssurveys (KIGGS). Dtsch Ärztebl 2007;104:A2944-A2040.

34 Lange D, Plachta-Danielzik S, Landsberg B, Muller MJ: Social inequality, migration, and healthy environments as determinants of overweight of children and adolescents. Results of the Kiel Obesity Prevention Study (KOPS) (in German. Bundesgesundheitsbl Gesundheitsforsch Gesundheitsschutz 2010;53:707-715.

35 Nagel G, Wabitsch M, Galm C, Berg S, Brandstetter S, Fritz M, Klenk J, Peter R, Prokopchuk D, Steiner R, Stroth S, Wartha O, Weiland SK, Steinacker J: Determinants of obesity in the Ulm Research on Metabolism, Exercise and Lifestyle in Children (URMEL-ICE). Eur J Pediatr 2009;168:1259-1267.

36 Kuepper-Nybelen J, Lamerz A, Bruning N, Hebebrand J, Herpertz-Dahlmann B, Brenner H: Major differences in prevalence of overweight according to nationality in preschool children living in Germany: determinants and public health implications. Arch Dis Child 2005;90:359-363.

37 Ogden CL, Carroll MD, Curtin LR, McDowell MA, Tabak CJ, Flegal KM: Prevalence of overweight and obesity in the United States, 1999-2004. JAMA 2006;295:1549-1555.

38 Besharat Pour M, Bergstrom A, Bottai M, Kull I, Wickman M, Hakansson N, Wolk A, Moradi T: Effect of parental migration background on childhood nutrition, physical activity, and body mass index. J Obes 2014;2014: 406529.

39 Fredriks AM, Van Buuren S, Sing RA, Wit JM, Verloove-Vanhorick SP: Alarming prevalences of overweight and obesity for children of Turkish, Moroccan and Dutch origin in the Netherlands according to international standards. Acta Paediatr 2005;94:496-498.

40 Saxena S, Ambler G, Cole TJ, Majeed A: Ethnic group differences in overweight and obese children and young people in England: CROSS sectional survey. Arch Dis Child 2004;89:30-36. 
Hilpert et al.: Sociocultural Influence on Obesity and Lifestyle in Children: A Study of Daily Activities, Leisure Time Behavior, Motor Skills, and Weight Status

41 Lange M, Kamtsiuris P, Lange C, Schaffrath Rosario A, Stolzenberg H, Lampert T: Sociodemographic characteristics in the German health interview and examination survey for children and adolescents (KIGGS) - operationalisation and public health significance, taking as an example the assessment of general state of health (in German). Bundesgesundheitsbl Gesundheitsforsch Gesundheitsschutz 2007;50:578-589.

42 Boos-Nünning U, Karakaşoğlu Y: Kinder und Jugendliche mit Migrationshintergrund im Sport; in Schmidt W, Hartmann-Tews I, Brettschneider W-D (eds): Erster deutscher Kinder- und Jugendsportbericht. Schorndorf, Hofmann, 2003, pp 319-338.

43 Woll A, Kurth BM, Opper E, Worth A, Bos K: The 'Motorik-Modul' (MoMo): physical fitness and physical activity in German children and adolescents. Eur J Pediatr 2011;170:1129-1142.

44 Hamer M, Chida Y: Active commuting and cardiovascular risk: a meta-analytic review. Prev Med 2008;46: 9-13.

45 Klesges LM, Baranowski T, Beech B, Cullen K, Murray DM, Rochon J, Pratt C: Social desirability bias in selfreported dietary, physical activity and weight concerns measures in 8- to 10-year-old African-American girls: results from the Girls Health Enrichment Multisite Studies (GEMS). Prev Med 2004;38(suppl):S78-87.

46 Westerterp KR: Assessment of physical activity: a critical appraisal. Eur J Appl Physiol 2009;105:823-828.

47 Bryant MJ, Lucove JC, Evenson KR, Marshall S: Measurement of television viewing in children and adolescents: a systematic review. Obes Rev 2007;8:197-209.

48 Klitsie T, Corder K, Visscher TL, Atkin AJ, Jones AP, van Sluijs EM: Children's sedentary behaviour: descriptive epidemiology and associations with objectively-measured sedentary time. BMC Public Health 2013;13:1092.

49 Stephens J, Allen J: Mobile phone interventions to increase physical activity and reduce weight: a systematic review. J Cardiovasc Nurs 2013;28:320-329.

50 Gilmore LA, Duhe AF, Frost EA, Redman LM: The technology boom: a new era in obesity management. J Diabetes Sci Technol 2014;8:596-608.

51 Dunton GF, Dzubur E, Kawabata K, Yanez B, Bo B, Intille S: Development of a smartphone application to measure physical activity using sensor-assisted self-report. Front Public Health 2014;2:12.

52 Shrewsbury V, Wardle J: Socioeconomic status and adiposity in childhood: a systematic review of crosssectional studies 1990-2005. Obesity (Silver Spring) 2008;16:275-284.

53 Sobal J: Obesity and socioeconomic status: a framework for examining relationships between physical and social variables. Med Anthropol 1991;13:231-247.

54 Yan T, Curtin R, Matthew Jans M: Trends in income nonresponse over two decades. J Off Stat 2010;26:145164.

55 Dobbins M, De Corby K, Robeson P, Husson H, Tirilis D: School-based physical activity programs for promoting physical activity and fitness in children and adolescents aged 6-18. Cochrane Database Syst Rev 2009; 1:CD007651.

56 Golan M, Kaufman V, Shahar DR: Childhood obesity treatment: targeting parents exclusively v. parents and children. Br J Nutr 2006;95:1008-1015.

57 Munsch S, Roth B, Michael T, Meyer AH, Biedert E, Roth S, Speck V, Zumsteg U, Isler E, Margraf J: Randomized controlled comparison of two cognitive behavioral therapies for obese children: mother versus mother-child cognitive behavioral therapy. Psychother Psychosom 2008;77:235-246.

58 Prochaska JO, DiClemente CC: Stages of change in the modification of problem behaviors. Prog Behav Modif 1992;28:183-218.

59 Mason HN, Crabtree V, Caudill P, Topp R: Childhood obesity: a transtheoretical case management approach. J Pediatr Nurs 2008;23:337-344.

60 Rodriguez Caro A, Gonzalez Lopez-Valcarcel B: The economic implications of interventions to prevent obesity (in Spanish). Revista Espanola de Salud Publica 2009;83:25-41. 